\title{
Risk Factors Analysis and Angiographic Profile in Postmenopausal Women with Coronary Artery Disease
}

\author{
AAS Majumder ${ }^{1}$, S Nasrin², AQM Reza ${ }^{1}$, MAU Chowdhury ${ }^{1}$ \\ ${ }^{1}$ Department of Cardiology, NICVD. ${ }^{2}$ Department of Cardiology, BIRDEM
}

\begin{abstract}
Keywords: $\quad$ Background : Postmenopausal women are at greater risk for coronary artery disease (CAD) than Risk factor, Coronary artery disease, Postmenopausal women, Angiographic profile. premenopausal women. This may be due to deprivation of estrogen, which acts directly and indirectly on the vasculature. In light of this finding the aim of the study was to find the relation of serum estrogen level with severity of atherosclerotic lesion and number of risk factors in CAD among postmenopausal women.

Methods: One hundred postmenopausal women undergoing coronary angiography (CAG) were studied. Among them 50 patients with estrogen level $\leq 25 \mathrm{pg} / \mathrm{ml}$ constituted study Group I and another 50 postmenopausal women with $>25 \mathrm{pg} / \mathrm{ml}$ constituted study Group II. Serum estrogen level was measured by radioimmunoassay. Other important risk factors like dyslipidaemia, diabetes mellitus, hypertension, family history of CAD, smoking and waist circumference were evaluated between the 2 groups of patients. CAG findings were analyzed by eye estimation and by Gensini score.

Results: All the risk factors were significantly higher in Group I patients than that of Group II. Among the risk factors hypertension was most prevalent (64\%) in Group I and dyslipidaemia (40\%) in Group II. Multivariate regression analysis showed that serum estrogen was a strong and an independent predictor of $C A D(p=0.001)$ when considered with other standard risk factors. Association between the angiographic severity of CAD and serum estrogen level were evaluated and negative correlation was observed, i.e. lower the serum estrogen level higher the vessel score.

Conclusion: In postmenopausal women serum estrogen level is a strong \& an independent predictor of CAD. It is also found that low estrogen group of postmenopausal women with CAD have more severe atherosclerotic lesions in comparison to the group with normal estrogen level.
\end{abstract}

(Cardiovasc.j. 2009; 1(2) : 161-164)

\section{Introduction:}

Several epidemiological studies have shown that independent of diverse lifestyle, diet and other risk factors, postmenopausal women are at greater risk for coronary artery disease than pre menopausal women. It is believed that this detrimental effect is due to the deprivation of endogenous hormonal action, namely estrogen, which acts directly and indirectly on the vasculature. ${ }^{1}$ The average lifetime risk for cardiovascular disease (CVD) in women is very high, approaching 1 in 2 , so prevention is important in all women. Even the presence of a single risk factor at 50 years of age is associated with a substantially increased lifetime absolute risk for CVD \& shorter duration of survival.

Alterations in lipid metabolism that are attributable to estrogen deficiency are thought to be a substantial component of the increase in coronary heart disease (CHD) risk in post menopausal women. ${ }^{2}$ Overt diabetes is associated with a greater increase in risk for atherosclerosis in women than in men. The presence of diabetes tends to attenuate any gender-related differences in cardiovascular morbidity and mortality. ${ }^{3}$

Recent data suggest that women develop high blood pressure, especially systolic hypertension, at an increased rate as they age. For this reason, it has been suggested that the loss of reproductive hormones associated with postmenopausal status is a risk factor for hypertension. ${ }^{4}$

Except for female hormonal status, no CHD risk factors are exclusively concerned with women. However the relatively short list of interrelated variables that exert a stronger effect on female than male risk includes diabetes, low HDL cholesterol and high TG.

So, by measuring serum estrogen level, we may identify a high-risk group in postmenopausal patients. Studies demonstrating detailed angiographic pattern of CAD severity with serum estrogen level and correlation with risk factors are important to understand in postmenopausal

Address of correspondence: Prof A A S Majumder, Department of Cardiology, NICVD, Dhaka, Bangladesh 
women. In this regard there was no study in our country. So, such a study may be quite reasonable and time-worthy.

\section{Materials and Methods:}

This is an observational study and was carried out for a period of 10 months starting from Feb 2007 to Dec 2007. A total of 100 postmenopausal women with coronary artery disease undergoing CAG were studied. Among them 50 patients with low estrogen level (i.e. $\leq 25 \mathrm{pg} / \mathrm{ml}$ ) constituted study Group I and another 50 postmenopausal women with normal estrogen level for their menopausal status with CAD (i.e. $>25 \mathrm{pg} / \mathrm{ml}$ ) constituted study Group II.

Serum estrogen level was measured by radioimmunoassay. Some other important risk factors like dyslipidaemia, diabetes mellitus, hypertension, family history of CAD, smoking \& waist circumference were evaluated between the 2 groups of patients. Coronary angiographic findings were analyzed by eye estimation in standard view. By Gensini score the lesions were roughly classified \& scored accordingly. ${ }^{5}$ Vessels score ranged from 0 to 3 depending on the number of vessels involved with a significant stenosis $(50 \%$ or greater). $>50 \%$ stenosis in the LM coronary artery was considered as 2 -vessel disease. ${ }^{1}$

\section{Results:}

Comparative demographic and coronary risk factor variables between Group I and Group II postmenopausal women are shown in table 1 .

\section{Table-I}

Demographic and coronary risk factors profile of postmenopausal women

\begin{tabular}{lccc}
\hline Variable & $\begin{array}{c}\text { Group I } \\
(\mathrm{n}=50)\end{array}$ & $\begin{array}{c}\text { Group II } \\
(\mathrm{n}=50)\end{array}$ & $\mathrm{p}$ Value \\
\hline Mean age & $\begin{array}{c}(56.6 \pm 5.7) \\
\text { years }\end{array}$ & $\begin{array}{c}(56.8 \pm 6.5) \\
\text { years }\end{array}$ & ${ }^{\mathrm{b}} 0.871^{\mathrm{NS}}$ \\
& $10 \%$ & $0 \%$ & ${ }^{\mathrm{a}} 0.028^{\mathrm{S}}$ \\
Smoker & $64 \%$ & $24 \%$ & ${ }^{\mathrm{a}} 0.001^{\mathrm{S}}$ \\
Hypertension & $58 \%$ & $20 \%$ & ${ }^{\mathrm{a}} 0.001^{\mathrm{S}}$ \\
Diabetes & $60 \%$ & $40 \%$ & ${ }^{\mathrm{a}} 0.045^{\mathrm{S}}$ \\
$\begin{array}{l}\text { Dyslipidaemia } \\
\text { Family history } \\
\text { of IHD }\end{array}$ & $44 \%$ & $16 \%$ & ${ }^{\mathrm{a}} 0.002^{\mathrm{S}}$ \\
$\begin{array}{l}\text { Central obesity } \\
\text { (>80cm waist }\end{array}$ & $88 \%$ & $60 \%$ & ${ }^{\mathrm{a}} 0.001^{\mathrm{S}}$ \\
circumference & & & \\
\hline
\end{tabular}

Group I: Low estrogen level $<25 \mathrm{pg} / \mathrm{ml}$, Group II: Normal estrogen level $>25 \mathrm{pg} / \mathrm{ml}, \mathrm{NS}=$ Not significant (pe"0.05), $\mathrm{S}=$ significant $(\mathrm{p}<0.05),{ }^{\mathrm{a}} \mathrm{p}$ Value reached from Chi square test, ${ }^{b} \mathrm{p}$ Value reached from unpaired t test

\section{Table-II}

Multivariate regression analysis of risk factors of CAD among postmenopausal women

\begin{tabular}{lcc}
\hline Variable & $\beta$ - coefficient & $\mathrm{p}$ Value \\
\hline Hypertension & 0.845 & $0.010^{\mathrm{s}}$ \\
$\mathrm{DM}$ & 0.712 & $0.011^{\mathrm{s}}$ \\
Dyslipidaemia & 0.078 & $0.788^{\mathrm{NS}}$ \\
Positive family history IHD & 0.603 & $0.025^{\mathrm{s}}$ \\
Waist circumference & 0.000 & $0.998^{\mathrm{NS}}$ \\
Estrogen & 0.945 & $0.001^{\mathrm{s}}$ \\
\hline
\end{tabular}

No significant difference was present between two groups considering mean age. Regarding risk factors significant difference was present. Hypertension, DM, positive family history and estrogen were significantly $(p<0.05)$ related to the degree of severity of CAD but dyslipidaemia and waist circumference was not related to the degree of severity of CAD. Among them serum estrogen level was statistically highly significant $(\mathrm{p}<0.001)$. It was a strong and an independent predictor of coronary heart disease (table-II).

In Group I, majority of the patients presented with unstable angina (40.0\%) followed by chronic stable angina (36.0\%), STEMI (10.0\%) and NSTEMI (4.0\%). Almost similar pattern of diagnosis was found in Group II patients.

Biochemical profile of the study population revealed that the mean fasting and post-prandial blood sugar was $6.3 \pm 2.0 \mathrm{mmol} / \mathrm{L}$ and $10.4 \pm 4.0$ $\mathrm{mmol} / \mathrm{L}$ in Group I and $4.7 \pm 0.7 \mathrm{mmol} / \mathrm{L}$ and $6.8 \pm 2.3 \mathrm{mmol} / \mathrm{L}$ in Group II respectively. The mean of total cholesterol was $(206.1 \pm 53.5) \mathrm{mg} / \mathrm{dl}$, LDL-C was $(153.7 \pm 43.9) \mathrm{mg} / \mathrm{dl}$, TG level was (195.3 \pm 63.0$) \mathrm{mg} / \mathrm{dl}$ and HDL-C level was (40.8 \pm 4.2$)$ $\mathrm{mg} / \mathrm{dl}$ in Group I and in Group II the values were $(174.5 \pm 27.2) \mathrm{mg} / \mathrm{dl},(124.1 \pm 25.3) \mathrm{mg} / \mathrm{dl}$, $(170.8 \pm 97.9) \mathrm{mg} / \mathrm{dl}$ and $(55.0 \pm 11.1) \mathrm{mg} / \mathrm{dl}$ respectively. Angiographic severity of CAD is shown in Table 3. 
Table-III

Mean Angiographic severity index.

\begin{tabular}{lccc}
\hline & $\begin{array}{c}\text { Group I } \\
(\mathrm{n}=50)\end{array}$ & $\begin{array}{c}\text { Group II } \\
(\mathrm{n}=50)\end{array}$ & $\mathrm{p}$ Value \\
\hline $\begin{array}{l}\text { Mean of total } \\
\text { score (Mean } \pm \mathrm{SD})\end{array}$ & $(21.6 \pm 17.5)$ & $(4.3 \pm 1.9)$ & $0.001^{\mathrm{S}}$ \\
$\begin{array}{l}\text { Mean of diseased } \\
\text { vessels (Mean } \pm \mathrm{SD})\end{array}$ & $(2.66 \pm 2.5)$ & $(1 \pm 0.6)$ & $0.001^{\mathrm{S}}$ \\
$\begin{array}{l}\text { Mean vessel score } \\
(\text { Mean } \pm \mathrm{SD})\end{array}$ & $(2.5 \pm 0.9)$ & $(1 \pm 1.2)$ & $0.001^{\mathrm{S}}$ \\
\hline
\end{tabular}

The mean of total score was significantly higher in Group I ( $p<0.05)$. It was also evident that Group I had higher number of diseased vessels as compared to Group II. The number of diseased vessels was 132 in Group I and 50 in Group II respectively. Regarding vessel score, the scoring was higher in Group I, 52.0\% patients had score 3, whereas this value was 18\% in Group II. In Group I, 'score 0' was $2.0 \%$ and in Group II it was $52.0 \%$. In this study association between the severity of CAD in the angiography and current estrogen levels of the study population was evaluated by the values of Pearson's correlation coefficient, which was -0.4299 . This is significant $(\mathrm{p}<0.05)$.

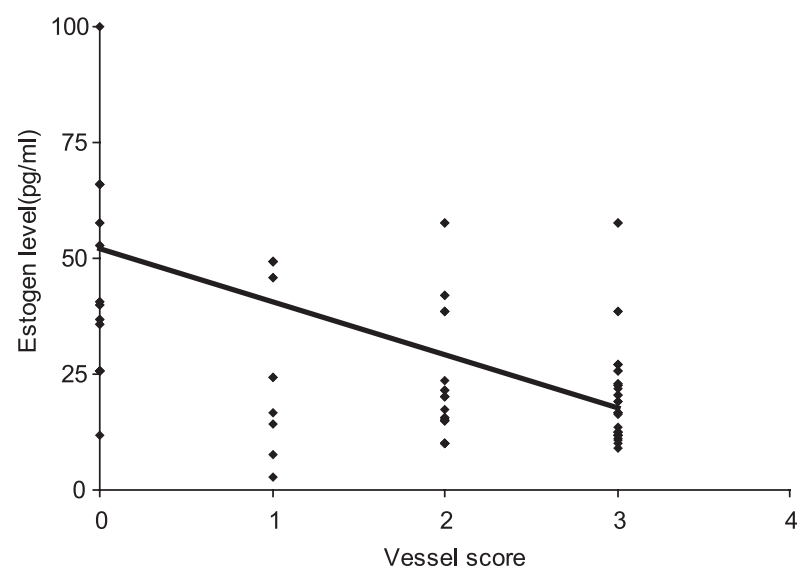

Fig.-1: The scatter diagram shows significant negative relationship $(r=-0.4299)$ between estrogen level and vessel score of the study population.

\section{Discussion:}

The present study was an observational study conducted in the National Institute of Cardiovascular Diseases (NICVD), Dhaka.

The aim of the study was to compare the severity of coronary artery disease in a selected group of postmenopausal women (natural menopause) who were divided into two groups. Group I with low estrogen level in respect to their menopausal status and Group II with normal estrogen level and association of some selected risk factors with this low estrogen level. A total of 100 postmenopausal women undergoing coronary angiography were studied.

All the risk factors were significantly higher in Group I patients than that of Group II. Among the risk factors hypertension was most prevalent (64\%) in Group I, i.e. low estrogen group. In normal estrogen group, it is the dyslipidaemia (40\%). Normal estrogen group had lower frequency of diabetes, dyslipidaemia, hypertension, positive family history of premature coronary disease, central obesity as revealed by waist circumference determination and none of them were smoker. This data was similar to those found by Morise, ${ }^{13}$ who found that estrogen status negative women had a higher frequency of diabetes, dyslipidaemia, hypertension and positive family history.

Lipid profile including total cholesterol and HDLC showed statistically significant difference between the two groups. But LDL-C and TG though higher in low estrogen group but the difference was not statistically significant.

Saltiki et al. and other authors also found inverse relationship of total cholesterol with serum estrogen level which matched with that of our study. ${ }^{1,6-12}$ Positive associations were found with the classical predisposing factor for CAD such as hypertension, diabetes mellitus, hyperlipidemia, positive family history of coronary artery disease with serum estrogen level and thus agree with the reports of that one of saltiki et al. who found similar associations with the classical predisposing factors for CAD with serum estrogen level.

Multivariate regression analysis showed that serum estrogen was a strong and an independent predictor of coronary heart disease $(p=0.001)$ when considered with other standard risk factors. Morise reevaluate Estrogen Status (ES) as a marker of prognosis in women showed that ES was an independent marker of risk $(p<0.001)$ when considered with other standard risk factors, which was in accordance with our findings. ${ }^{13}$

In this study the mean duration of menopause in low estrogen group was $(8.4 \pm 6.1)$ years with a range 
of (1 to 22) years and in normal estrogen group it was $(6.3 \pm 6.8)$ years with same range as that of Group I population. This duration had correlation with severity of stenosis. In low estrogen group mean vessel score was $(2.5 \pm 0.9)$ and in that of normal estrogen group it was (1.0 \pm 1.2$)$.

This finding matched with that one found by Saltiki et al. who found that time since menopause tended to be higher in women who had severe stenosis in more than one vessel, however this difference wasn't statistically significant. ${ }^{1}$ It was found that women with low estrogen level had more severe disease on coronary angiography in comparison to normal estrogen level as reflected by a higher coronary artery score. Mean scores were (2.5 \pm $0.9)$ vs $(1.0 \pm 1.2)$ respectively in two groups, which was statistically significant.The coronary artery disease in low estrogen women was found to be significantly more diffuse than that of normal estrogen group $(14 \%$ vs $2 \%, \mathrm{p}<0.05)$. Diffuse involvement was more common in $\mathrm{LAD}$ ( $10 \%$ vs $2 \% ; \mathrm{p}>0.05)$ followed by RCA (6\% vs $2 \% ; \mathrm{p}>0.05$ ) and LCX ( $4 \%$ vs $2 \%$; $p>0.05$ ).

Association between the severity of coronary heart disease in the angiography and current estrogen levels were evaluated and negative correlation was observed. Concerning endogenous estrogen levels no association have been found in the majority of studies, contradict with the results reported here. ${ }^{14-16}$ This was not unexpected as most women were postmenopausal and current estrogen levels were thus low. Only one study showed that current levels of endogenous estrogen are associated with cardiovascular disease in postmenopausal women. ${ }^{17}$

So, this study supports the notion of a protective effect of endogenous estrogen on vascular health, in this selected group of postmenopausal women $\&$ it is an important marker of cardiac risk in post menopausal women with symptoms of suspected coronary disease.

\section{Conclusion:}

In postmenopausal women serum estrogen level is a strong \& an independent predictor of CAD. It is also found that low estrogen group of postmenopausal women with $\mathrm{CAD}$ have more severe atherosclerotic lesions in comparison to the group with normal estrogen level.

\section{References:}

1. Saltiki K, Doukas C, Kanakakis J, Anastasiou E, Mantzou E, Alevizaki M. Severity of cardiovascular disease in women: Relation with exposure to endogenous estrogen. Maturitus- The European Menopause Journal 2006; 55: 51-57.

2. Collins P. 2007, HDL-C in post-menopausal women: An important therapeutic target. International Journal of Cardiology 2007; Retrieved June 30, 2007, from www.elsevier.com/locate/ijcard.

3. Foody JM. Cardiovascular disease in women: Coronary artery disease. Women Health 2006; 46: 733-749.

4. Gierach GL, Johnson BD, Merz CBN et al. Hypertension, Menopause, and Coronary Artery disease, Risk in the women's Ischaemic Syndrome Evaluation (WISE) study. J Am Coll Cardiol 2006; 47: 505-585.

5. Deligonul U, Kern MJ, Roth R. Angiographic data. In: Kern MJ. Ed. The Cardiac Catheterization Hand book. Mosby, St. Louis, 2003: 217-325.

6. $\mathrm{Hu}$ FB, Grodstein F, Hennekens CH, et al. Age at natural menopause and risk of cardiovascular disease. Arch Intern Med 1999; 159:1061-1066.

7. Rosenberg L, Miller DR, Kaufman DW, et al. Myocardial infarction in women under 50 years of age. JAMA 1983;250:2801-2806.

8. Stampfer MJ, Hu FB, Manson JE, Rimm EB, Willett WC. Primary prevention of coronary heart disease in women through diet and lifestyle. $N$ Engl J Med 2000;343:16-22.

9. Brochier ML, Arwidson P. Coronary heart disease risk factors in women. Eur Heart $J$ 1998;19:A45-52.

10. Shelley JM, Green A, Smith AM, et al. Relationship of endogenous sex hormones to lipids and blood pressure in mid-aged women. Ann Epidemiol 1998;8:39-45.

11. Hauner H, Bognar E, Blum A. Body fat distribution and its association with metabolic and hormonal risk factors in women with angiographically assessed coronary artery disease. Evidence for the presence of a metabolic syndrome. Atherosclerosis 1994;105:209-216.

12. Gensini GF, Comeglio M, Colella A. Classical risk factors and emerging elements in the risk profile for coronary artery disease. Eur Heart J 1998;19:A53-61.

13. Morise AP. Assessment of Estrogen Status as a marker of prognosis in women with symptoms of suspected coronary artery disease presenting for stress testing. Am J Cardiol 2006;97: 367-371.

14. Barrett-Connor E, Goodman-Gruen D. Prospective study of endogenous sex hormones and fatal cardiovascular disease in postmenopausal women. $B M J$ 1995;311:1193-1196.

15. Philips GB, Pinkernell BH, Jing TY. Relationship between serum sex hormones \& coronary artery disease in postmenopausal women. Arterioscler Thromb Vasc Biol 1997; 17: 695-701.

16. Rexrode KM, Manson JE, Lee IM, et al. Sex hormone levels \& risk of cardiovascular events in postmenopausal women. Circulation 2003; 108:1688-1693.

17. Guthrie JR, Taffe JR, Lehert P, Burger HG, Dennerstein L. Association between hormonal changes at menopause and the risk of a coronary event : a longitudinal study. Menopause: The Journal of the North American Menopause Society 2004; 11: 315-322. 